\title{
Flora da Bahia: Rapateaceae
}

\author{
Fernanda Afonso Santana ${ }^{1, a}$, Daniela Santos Carneiro-Torres ${ }^{1 *}$, Rafael Gomes Barbosa-Silva ${ }^{1, b}$, Ana Maria \\ Giulietti $^{1,2,3, c}$ \& Reyjane Patrícia de Oliveira ${ }^{1, d}$
}

${ }^{1}$ Programa de Pós-graduação em Botânica, Departamento de Ciências Biológicas, Universidade Estadual de Feira de Santana, Feira de Santana, Bahia, Brasil.

${ }^{2}$ Instituto Tecnológico Vale de Desenvolvimento Sustentável, Belém, Pará, Brasil.

${ }^{3}$ Royal Botanic Gardens, Kew, United Kingdom.

Resumo - É apresentada aqui a flora de Rapateaceae do estado da Bahia, Brasil. São reconhecidas duas espécies de Rapatea, R. paludosa e $R$. pycnocephala, e uma de Cephalostemon, C. angustatus. São apresentados chave de identificação, descrições, ilustrações e comentários para os táxons, bem como um mapa de distribuição geográfica para as espécies no estado.

Palavras-chave adicionais: plantas anfíbias, Brasil, taxonomia.

Abstract (Flora of Bahia: Rapateaceae) - The flora of the Rapateaceae from Bahia State, Brazil, is presented here. Two species of Rapatea, $R$. paludosa and R. pycnocephala, and one species of Cephalostemon, C. angustatus, are recognized. An identification key, descriptions, illustrations and comments for taxa are presented, as well as a map of species distribution in the state.

Additional key words: amphibious plants, Brazil, taxonomy.

\section{RAPATEACEAE}

Ervas perenes, geralmente paludosas ou raramente epífitas; rizomas prostrados a eretos. Folhas em roseta, espiraladas ou dísticas, ensiformes, pecioladas ou sésseis, bainha conduplicada, lâmina rígida, lanceolada ou linear. Inflorescências capituliformes, espiciformes ou secundifloras, axilares ou terminais, congestas, mucilaginosas, escapo longo ou curto, 1 ou 2 espatas livres ou conatas; espiguetas numerosas, sésseis ou pedunculadas, envoltas por numerosas bractéolas estéreis, imbricadas e com uma única flor terminal. Flores trímeras, bissexuadas, actinomorfas, raramente zigomorfas, diclamídeas, heteroclamídeas, sésseis ou pediceladas; sépalas 3, rígidas, papiráceas ou raramente membranáceas, livres ou conatas, verdes ou castanhas; pétalas 3, efêmeras, frequentemente conatas na base, lobos lanceolados, ovais ou obovais, brancas, amarelas ou vermelhas; estames 6 , conatos na base, às vezes adnatos à corola, anteras 2-tecas, 1-4 poros apicais ou subapicais; ovário súpero, 3-carpelar, 3-locular, placentação basal ou axilar, 1-8 óvulos por lóculo, estilete filiforme. Frutos cápsulas loculicidas; sementes 2-10 por fruto, ovais ou oblongas, longitudinalmente estriadas ou não, endosperma farináceo.

Rapateaceae está incluída na ordem Poales (Stevens 2012; APG IV 2016) e compreende 17 gêneros e cerca de 100 espécies predominantemente neotropicais, com

\footnotetext{
*Autora para correspondência: dscarneiro@hotmail.com;

afernandaafonsos@hotmail.com; brafa.g29@gmail.com;

canagiulietti@hotmail.com; ${ }^{\mathrm{r}}$ rpatricia@uefs.br

Editor responsável: Alessandro Rapini

Submetido: 24 nov. 2017; aceito: 28 dez. 2017
}

Publicação eletrônica: 28 dez. 2017; versão final: 13 abr. 2018 exceção da africana Maschalocephalus dinklagei Gilg \& Schum. (Berry 2004; Givnish et al. 2004; Monteiro 2011). O principal centro de diversidade da família é o Escudo das Guianas, onde ocorrem 14 gêneros e 41 espécies (Berry 2004; Smith et al. 2004; Forzza \& Costa 2005). No Brasil, a família ainda é pouco estudada e os trabalhos têm focado especialmente floras estaduais e novidades taxonômicas (Rodrigues 2015; Praia et al. 2016; Berry \& Krahl 2017). Segundo Praia et al. (2017), está representada por nove gêneros e 41 espécies no Brasil, ocorrendo preferencialmente em brejos, campinaranas, campos rupestres, matas de galeria e veredas. Apenas o gênero Rapatea era referido para a Bahia, representado por $R$. paludosa $\mathrm{e}$ $R$. pychnocephala; Cephalostemon é registrada aqui pela primeira vez na Bahia e na Região Nordeste.

\section{Chave para as espécies}

1. Folhas com lâmina linear; espatas lanceoladas; bractéolas com ápice aristado

........................... 1.1. Cephalostemon angustatus

1'. Folhas com lâmina lanceolada; espatas deltoides ou sagitiformes; bractéolas com ápice agudo ou acuminado

2. Rapatea

2. Inflorescências subglobosas; espiguetas elipsoides a oblongoides, conspicuamente pedunculadas; pedicelo 10-12 $\mathrm{mm}$ compr.; bractéolas com ápice acuminado ...................... 1. R. paludosa

2'. Inflorescências globosas; espiguetas elipsoides, sésseis a inconspicuamente pedunculadas; pedicelo 3-5 mm compr.; bractéolas com ápice agudo 2.2. R. pycnocephala

1. Cephalostemon R.H.Schomb.

Ervas paludosas, cespitosas, glabras, raízes esponjosas. Folhas em rosetas, espiraladas a dísticas, 
lâmina linear. Inflorescências capituliformes, globosas ou subglobosas, terminais, 1 ou 2 escapos por planta, longos, eretos, cilíndricos, 2 espatas lanceoladas, livres na base; espiguetas sésseis, bractéolas com ápice aristado. Flores actinomorfas, sésseis; sépalas conatas na base, oval-lanceoladas; pétalas conatas na base, amarelas; estames adnatos às pétalas, anteras oblongas, 4-poradas; ovário globoso, 3 óvulos férteis, placentação basal, estilete com ápice triangular, estigma capitado, epapiloso. Cápsulas ovoides; sementes 3.

Cephalostemon é um gênero sul-americano, ocorrendo na Venezuela, Suriname, Bolívia e Brasil (Berry 2004). Inclui cinco espécies; todas ocorrem no Brasil, especialmente nas Regiões Norte (Amazonas, Amapá, Pará, Roraima e Tocantins), Centro-Oeste (Distrito Federal, Goiás, Mato Grosso e Mato Grosso do Sul) e Sudeste (Minas Gerais e São Paulo) (Monteiro 2017).

\subsection{Cephalostemon angustatus Malme, Ark. Bot.} 26A(9): 11. 1934.

Figuras 1 e $2 \mathrm{~A}-\mathrm{D}$.

Ervas, $37-80 \mathrm{~cm}$ alt. Folhas com lâmina linear, plana, 20-60 $(-90) \times 0,2-0,4 \mathrm{~cm}$, ápice agudo; escapo 35-78 cm compr. Inflorescências subglobosas; espatas livres, 2,5-4 × 0,3-0,4 cm, base cordada, ápice agudo ou acuminado; bractéolas 7,5-11,5 mm compr., ápice aristado. Flores com sépalas $6-8 \times$ ca. $3 \mathrm{~mm}$; pétalas amplamente obovadas, ca. 1,1 cm compr.; filetes ca. 2 mm compr., anteras ca. $2 \mathrm{~mm}$ compr.; ovário globoso, estilete agudo, ca. $6 \mathrm{~mm}$ compr. Cápsulas com sementes ovoides, eretas, não estriadas.

Trata-se do primeiro registro de Cephalostemon para a Bahia, sendo $C$. angustatus anteriormente referida para os estados de Goiás, Mato Grosso, Minas Gerais, Tocantins e Distrito Federal (Monteiro 2017). Na Bahia, foi encontrada na região oeste do Estado. D2 e G2: veredas, em área de cerrado. Floração e frutificação de abril a setembro.

Material selecionado - Cocos, $14^{\circ} 40^{\prime} 20^{\prime \prime} \mathrm{S}, 45^{\circ} 49^{\prime} 57^{\prime \prime} \mathrm{W}, 12$ dez. 2001 (fl.), Walter 4951 (CEN, RB); Barreiras, 11'52'44"S, 4549'39”W, 760 m s.n.m., s.d. (fl.), Cotrim 1034 (HUEFS).

Cephalostemon angustatus é tipicamente encontrada em áreas de cerrado, sendo morfologicamente similar a $C$. riedelianus Koern., que ocorre em áreas de campo rupestre. Distingue-se daquela espécie principalmente porque $C$. riedelianus inclui plantas mais robustas, até $1,4 \mathrm{~m}$ de altura, com espatas maiores, de 3,5 a 9,0 mm. Entretanto, Pirani \& Giulietti (1989) relataram plantas mais ou menos robustas em populações de $C$. riedelianus na Serra do Cipó. Dessa maneira, um estudo comparativo mais detalhado para esse par de espécies parece necessário.

\section{Rapatea Aubl.}

Ervas paludosas, cespitosas, glabras ou pubescentes. Folhas dísticas, equitantes, lâmina oblongo-lanceolada ou lanceolada. Inflorescências capituliformes, globosas ou subglobosas, terminais ou axilares, 1-3 escapos por planta, eretos, achatados, 2 espatas deltoides ou sagitiformes, livres ou conatas na base; espiguetas sésseis ou pedunculadas, bractéolas com ápice agudo ou acuminado. Flores actinomorfas, sésseis ou pediceladas; sépalas conatas na base, ovallanceoladas; pétalas conatas na base, amarelas ou raramente brancas; estames adnatos às pétalas, anteras lineares ou oblongas, 1-porada; ovário obovado, 1 óvulo fértil +2 ou 3 abortados, placentação basal, estilete com ápice agudo, estigma capitado, papiloso. Cápsulas obovoides; sementes 1-3.

Rapatea ocorre essencialmente nas Guianas e no Brasil (Forzza \& Costa 2005). Inclui cerca de 27 espécies e, segundo Praia (2017), são registradas 14 espécies no Brasil, distribuídas nos estados da Região Norte (Acre, Amazonas, Amapá, Pará, Rondônia, Roraima e Tocantins), Nordeste (Bahia, Maranhão e Piauí) e Centro-Oeste (Mato Grosso e Mato Grosso do Sul).

2.1. Rapatea paludosa Aubl., Hist. P1. Guiane 1: 305; tab. 118. 1775.

Figuras 1 e 2E-G.

Ervas $42-52 \mathrm{~cm}$ alt. Folhas com lâmina lanceolada, 90-100 × 4-7 cm, ápice acuminado. Inflorescências subglobosas; escapo $45-50 \mathrm{~cm}$ compr., espatas unidas na base, $10-17 \times 4,5-6 \mathrm{~cm}$, deltoides, base cordada, ápice acuminado; espiguetas com pedúnculo 10-12 $\mathrm{mm}$ compr., oblongas ou oblanceoladas, bractéolas 10-16 mm compr., ápice acuminado. Flores com sépalas ca. $10 \times 4 \mathrm{~mm}$; pétalas amplamente obovadas, ca. 1,2 cm compr.; filetes 6-7 $\mathrm{mm}$ compr., face dorsal lisa, ápice agudo, antera ca. 2 mm compr., base papilosa, ápice agudo; estilete agudo, coloração uniforme, sem máculas. Cápsulas ca. $5 \mathrm{~mm}$ compr.; sementes elipsoides.

Rapatea paludosa é freqüente em florestas da porção norte da América do Sul (Forzza \& Costa 2005). No Brasil, está distribuída nos estados da Região Norte (Acre, Amazonas, Amapá, Pará, Rondônia e Tocantins), Nordeste (Bahia) e CentroOeste (Mato Grosso) (Praia 2017). E9, F8, F9, G8, G9, H8 e J8: especialmente ao longo do litoral, em área de brejos associadas a restingas. Floresce de julho a janeiro e frutifica de fevereiro a maio.

Material selecionado - Cairu, caminho para Mata de Abreu, 1329'30”'S, 3902'30”W, 12 jun. 2003 (fl.), Guedes \& Rigueira 10249 (ALCB, CEPEC, HRB); Camamu, povoado de Barcelos do Sul, jul. 2005 (fl., fr.), Miranda \& Silva 5142 (HUEFS, RB, UFRN); Catu, 1305'46”S, 38 47'06”'W, 27 set. 2011 (fl.), Matos 563 (HUEFS); Ilhéus, 1447'20”'S, 3902'58”'W, 31 jul. 2011 (fr.), Perdiz 868 (CEPEC); Itacaré, 14¹6'39”'S, 38 59'48”W, 22. mar. 2004 (fl., fr.), Mattos-Silva 4825 (CEPEC, UESC); Ituberá, 134'56”'S, 3908'57'W, 15 set. 2006 (fl., fr.), Guedes 12635 (ALCB); Jaguaripe, 1306' $48^{\prime}$ 'S, 38 $53^{\circ}$ '44”'W, 20 abr. 2011 (fl.), Ferreira s.n. (ALCB 114720); Maraú, 1406'11"S, 3900'53”W,

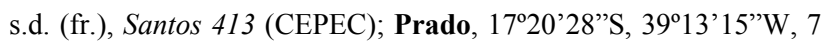


nov. 2009 (fl.), Carvalho 168 (CEPEC); Salvador, 1258'S, 38³0'W, 4 jun. 2012 (fl., fr.), Gomes et al. 1155 (ALCB); São Sebastião do Passé, 12³0'45”S, 38²9’43”W, 25 out. 1998 (fl.), Nascimento 202 (ALCB, CEPEC); Una, Ecoparque de Una, 15'10'02”S, 39 03'29'W, 23 jan. 2005 (fl.), Thomas et al. 14422 (CEPEC, NY); Uruçuca, 14³5’35”'S, 39¹7’04”'W, 24 ago. 1992 (fr.), Amorim 593 (CEPEC, NY).

$\mathrm{Na}$ Bahia, Rapatea paludosa pode ser facilmente distinta de $R$. pycnocephala por serem plantas menores e pelos caracteres da chave, especialmente as espiguetas pedunculadas.

2.2. Rapatea pycnocephala Seub. in Martius, Fl. Bras. 3(1): 128.1847.

Figuras 1 e $2 \mathrm{H}-\mathrm{K}$.

Ervas $82-85 \mathrm{~cm}$ alt. Folhas com lamina lanceolada, $80-82 \times 2-2,5 \mathrm{~cm}$, ápice agudo. Inflorescências globosas; escapo $80-83 \mathrm{~cm}$ compr, espatas livres, 7,5-12,5 × 2-2,5 cm, deltoides, base cordada, ápice agudo; espiguetas sésseis ou com pedúnculo 3-5 mm compr., obovoides, bractéolas 3-5 mm compr., ápice agudo. Flores com sépalas ca. $10 \times$ $4 \mathrm{~mm}$; pétalas amplamente obovadas, ca. $2 \mathrm{~cm}$ compr.; filetes ca. $4 \mathrm{~mm}$ compr., face dorsal papilosa, ápice agudo, anteras ca. $1 \mathrm{~mm}$ compr., base lisa, ápice truncado; estilete acuminado, com máculas castanhas espaçadas. Cápsulas ca. $5 \mathrm{~mm}$ compr., sementes elipsoides.

Endêmica do Brasil, distribui-se nos estados das Regiões Norte (Pará, Rondônia e Tocantins), CentroOeste (Distrito Federal, Goiás, Mato Grosso e Mato Grosso do Sul) e Nordeste (Bahia, Maranhão e Piauí) (Praia 2017). D2 e E2/3: áreas de brejo em matas de galeria na região oeste do estado. Floresce e frutifica de outubro a novembro.

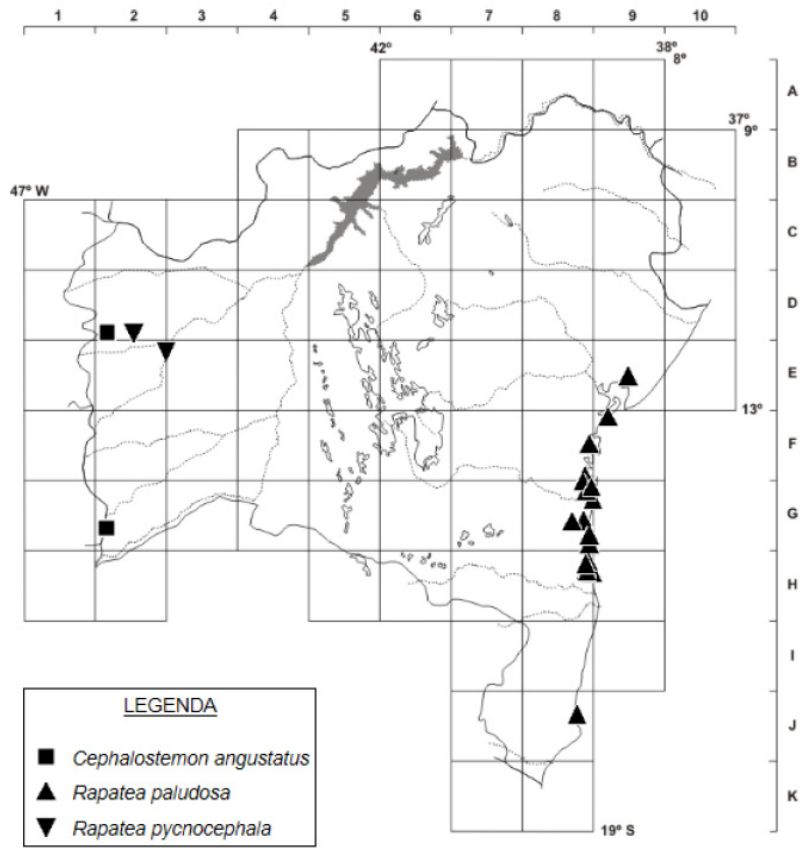

Figura 1. Distribuição geográfica de Cephalostemon angustatus, Rapatea paludosa e R. pycnocephala no estado da Bahia.
Material examinado - Barreiras, abaixo da Cachoeira do

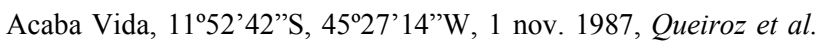
2060 (HRB, HUEFS, NY).

Para Praia et al. (2016), Rapatea pycnocephala difere das outras espécies do gênero pelas espatas decíduas na maturação. Entretanto, nos materiais examinados aqui, as espatas se apresentaram persistentes. As diferenças entre $R$. pycnocephala e $R$. paludosa são apresentadas nos comentários da outra espécie.

\section{Agradecimentos}

Aos curadores dos herbários, pelo acesso às coleções, especialmente o HUEFS e CEPEC. Ao CNPq, pelas bolsas de Produtividade em Pesquisa concedidas a AMG (PQ Sênior) e RPO (PQ-1D). À FAPESB, pelo auxílio fínanceiro ao Projeto Flora da Bahia (APR0162/2007), e ao CNPq pelo apoio ao PROTAX (562278/2010-9) e ao projeto Flora da Bahia $(483909 / 2012-2)$.

\section{REFERÊNCIAS}

APG IV 2016. An update of the Angiosperm Phylogeny Group classification for the orders and families of flowering plants. Botanical Journal of the Linnean Society 161: 105-121.

Berry, P.E. 2004. Rapateaceae. In: P.E. Berry, K. Yatskievych \& B.K. Holst (eds), Flora of the Venezuelan Guayana PoaceaeRubiaceae. Vol. 8. Missouri Botanical Gardens, Saint Louis, p. 413-472.

Berry, P.E. \& Krahl, A.H. 2017. A new species of Saxofridericia subgenus Acrotheca (Rapateaceae) from Amazonas State, Brazil. Phytotaxa 326(4): 284-288.

Forzza, R.C. \& Costa, M.A.S. 2005. Flora da Reserva Ducke, Amazonas, Brasil: Rapateaceae. Rodriguésia. 56(86): 177-181.

Givnish, T.J.; Millam, K.C.; Evans, T.M.; Hall, J.C.; Pires, J.C.; Berry, P.E. \& Sitsma, K.J. 2004. Ancient vicariance or recent long-distance dispersal? Inferences about phylogeny and South American-African disjunctions in Rapateaceae and Bromeliaceae based on $n d h f$ sequence data. International Journal of Plant Sciences. 165(4 Supp1.): S35-S54.

Monteiro, R.F. 2011. Neotropical Rapateaceae. In: W. Milliken, B. Klitgard \& A. Baracat (eds), Neotropikey - Interactive key and information resources for flowering plants of the Neotropics. Disponível em: http://www.kew.org/science/ tropamerica/neotropikey/families/Rapateaceae.htm; acesso em: 5 nov. 2017.

Monteiro, R.F. 2017. Cephalostemon. In: Flora do Brasil 2020, em construção. Jardim Botânico do Rio de Janeiro. Disponível em: $<$ http://floradobrasil.jbrj.gov.br/reflora/floradobrasi1/FB32489>; acesso em: 5 nov. 2017.

Pirani, J.R. \& Giulietti, A.M. 1989. Flora da Serra do Cipó, MinasGerais: Rapateaceae. Boletim de Botânica da Universidade de São Paulo 11: 171-174. 




Figura 2. A-D. Cephalostemon angustatus: A- hábito; B- inflorescência; C- espigueta; D- Bractéola. E-G. Rapatea paludosa: E- inflorescência; F- espigueta; G- bractéola. H-K. R. pycnocephala: H- hábito; I- inflorescência; J- espigueta; K- bractéola. (A-D- Cotrim 476; E-G- Miranda 5142; H-K- Queiroz 4096). 
Praia, T.S. 2017. Rapatea. In: Flora do Brasil 2020, em construção. Jardim Botânico do Rio de Janeiro. Disponível em: $<$ http://floradobrasil.jbrj.gov.br/reflora/floradobrasil/FB20643>; acesso em: 8 nov. 2017.

Praia, T.S.; Gil, A.S.B. \& Secco, R. 2016. Rapateaceae in the state of Pará, Brazil. Acta Botanica Brasilica 30(4): 628-643.

Praia, T.S.; Monteiro, R.F. \& Barbosa-Silva, R.G. 2017. Rapateaceae. In: Flora do Brasil 2020, em construção. Jardim Botânico do Rio de Janeiro. Disponível em: $<$ http://floradobrasil.jbrj.gov.br/reflora/floradobrasil/FB205>; acesso em: 6 nov. 2017.
Rodrigues, R.S. 2015. Notes on the taxonomy and nomenclature of Monotrema bracteatum (Rapateaceae). Boletim do Museu Integrado de Roraima 9: 19-22.

Stevens, P.F. 2012. Angiosperm Phylogeny Website. Version 12, July 2012 [and more or less continuously updated since]. Disponível em: http://www.mobot.org/MOBOT/research/ APweb/; acesso em: 30 out. 2017.

Stevenson, D.W. 2004. Rapateaceae. In: N. Smith, S.A. Mori, A. Henderson, D.W. Stevenson \& S.V. Heald (eds), Flowering Plants of the Neotropics. Princeton University Press, Princeton, p. 477-479.

\section{LISTA DE EXSICATAS}

Amorim, M. 529, 593 (2.1); Carvalho, D.N. 401 (2.1); Carvalho, G.M. 168 (2.1); Carvalho, M. 4259 (2.1); Cotrim, A. 218, 374, 451, 476, 1034, 1036, 1048 (1.1); Ferreira, P.A. s.n. ALCB 114720 (2.1); Fiaschi, P. 1058 (2.1); Gomes, F.S. 1155 (2.1); Guedes, M.L. 3183 , 9391, 10249, 12635 (2.1); Harley, R.M. 18278, 22093 (2.1); Hatschbach, G. 68538 (2.1); Jardim, J.B. 2760 (2.1); Jesus, J.A. 413 (2.1); Martinelli, G. 6054 (2.1); Matos E.N. 48, 563 (2.1); Mattos-Silva, L.A. 1066, 3670, 4639, 4825 (2.1); Melo, E. 4000 , 4003 (1.1); Miranda, A.M. 5142 (2.1) Mori, S.A. 11985, 13691 (2.1); Nascimento, A.F.S. 202 (2.1); Paixão, J.L. 517 (2.1); Perdiz, R.o. 868 (2.1); Pinheiro, R.S. 1483 (2.1); Posadas, R.C. 1784 (2.1); Queiroz, L.P. 2060, 4096 (2.2); Rapini, A. 2026 (1.1); Rigueira, D. s.n. ALCB 67976 (2.1); Rylands, A. 115 (2.1); Santana, S.C. 1112, 1125 (2.1); Santos, E.B. 144 (2.1); Santos, J.A. 413 (2.1); Santos, T.S. 1007, 2874, 3592 (2.1); Sobral, M. 5777, 5785 (2.1); Thomas, W.W. 9003, 14422 (2.1); Voeks, R. 23 (2.1); Walter, B.M.T. 4951 (1.1). 